\title{
Comorbidities as Risk Factors for Severe Disease in Hospitalized Elderly COVID-19 Patients by Different Age-Groups in Japan
}

\author{
Yusuke Asai $^{a}$ Hidetoshi Nomoto $^{\text {b, c }}$ Kayoko Hayakawa ${ }^{a, b}$

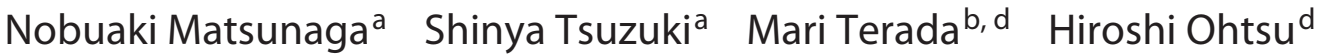 \\ Koji Kitajimad Kumiko Suzuki ${ }^{a}$ Tetsuya Suzukib,c Keiji Nakamurab \\ Shinichiro Morioka ${ }^{a, b, c}$ Sho Saito ${ }^{b}$ Fumitake Saito $^{e}$ Norio Ohmagaria, b, c \\ ${ }^{a} A M R$ Clinical Reference Center, National Center for Global Health and Medicine, Tokyo, Japan; bisease Control \\ and Prevention Center, National Center for Global Health and Medicine, Tokyo, Japan; 'Emerging and Reemerging \\ Infectious Diseases, Graduate School of Medicine, Tohoku University, Sendai, Japan; ${ }^{\mathrm{d} C e n t e r}$ for Clinical Sciences, \\ National Center for Global Health and Medicine, Tokyo, Japan; 'Department of Pulmonary Medicine, Eiju General \\ Hospital, Tokyo, Japan
}

\section{Keywords \\ Coronavirus disease $2019 \cdot$ Severe acute respiratory coronavirus 2 . Older people $\cdot$ Inpatients $\cdot$ Risk factors}

\begin{abstract}
Introduction: Old age is an independent risk factor (RF) for severe COVID-19; evidence for clinico-epidemiological characteristics among elderly COVID-19 patients is scarce. We aimed to analyze clinical and epidemiological characteristics and comorbidities associated with COVID-19 inpatients in age-stratified populations of an elderly COVID-19 cohort. Methods: We conducted a retrospective cohort study, using nationwide registry data of COVID-19 patients hospitalized before October 31, 2020 (major information entered in the registry as of December 28, 2020). Participants were divided by age according to the Japan Geriatrics Society and the Japan Gerontological Society: pre-old (65-74 years), old (7589 years), and super-old ( $\geq 90$ years). Multivariable logistic regression (MLR) analyses were conducted to identify stratified risk and relationships with comorbidities associated
\end{abstract}

with worse outcomes in different age-groups of elderly patients. Demographics and supportive care were evaluated by category. Results: Data of 4,701 patients from 444 hospitals were included. Most patients (79.3\%) had at least one comorbidity; the proportion of patients with hypertension was high in all categories. The proportion of patients with dementia, cardiovascular disease, and cerebrovascular disease increased with age. The percentage of patients who underwent invasive mechanical ventilation/extracorporeal membrane oxygenation was lower in the super-old group. In total, $11.5 \%$ of patients died (5.3\%, pre-old; $15.2 \%$, old; and $22.4 \%$, super-old). MLR showed that the risk of critical illness differed among age-groups. Male sex was a significant RF in all ages. Collagen disease, moderate to severe renal disorder, and dialysis were significant RFs in older patients, while hematological malignancies and metastatic tumors were more important RFs for severe disease in relatively younger patients. Most of the RFs for critical illnesses were associated with death. Conclusion: Differences in the epidemiological and clinical characteristics among the different age-groups were found.

(c) 2022 S. Karger AG, Basel 


\section{Introduction}

Severe acute respiratory coronavirus 2 first emerged in Wuhan, China, in December 2019, and the ongoing outbreak of COVID-19 has been a global concern [1]. To date, Japan has passed through the first and second waves [2] and has now progressed to the third wave of $\mathrm{CO}$ VID-19 [3]. The proportion of the elderly among all patients was higher in the first wave than that in the second wave, with higher mortality. Conversely, the second wave was characterized by a relatively low mortality rate and a large proportion of young people being infected, although the total number of infections is slightly larger than that in the first wave [2]. Regarding the third wave, since late October 2020, the number of patients recorded was more than 7,000 cases in a single day [4], breaking Japan's daily record. High-risk populations, including residents of long-term care welfare facilities for the elderly, have also been greatly affected by the pandemic.

Present evidence implies that certain conditions are associated with the risk of severe COVID-19. As patients age, the disease causes a more severe state [5-7]. In addition, a higher mortality rate was found in patients with underlying conditions [8]. Japan is a country with a "super-aged society," and the average life expectancy in 2019 ranked highly in the world: 87.4 years for women and 81.4 years for men [9]. While old age contributes to disease severity, the epidemiological characteristics of COVID-19 in elderly patients, including the very elderly population, remain unclear. In addition, evidence for stratified risk analysis and relationships with comorbidities in worse outcomes among the very elderly remains scarce. In this study, in an age-stratified COVID-19 elderly cohort in a nationwide registry in Japan, we aimed to elucidate the following: how clinical and epidemiological characteristics differ and what comorbidities are associated with severe COVID-19 in each age-group of elderly inpatients.

\section{Materials and Methods}

Data Collection and the Case Report Form

We used data from the COVID-19 Registry Japan (COVIREGI-JP) [10]. The details of data collection and the case report form are described elsewhere [10]. The study data were collected and managed using Research Electronic Data Capture, a secure, Webbased data capture application hosted at the Joint Center for Researchers, Associates and Clinicians (JCRAC) Data Centre of the National Center for Global Health and Medicine (NCGM) [11]. We used data from hospitalized cases before October 31, 2020, and all major data items as of December 28, 2020, similar to a previous report [10].

\section{Comorbidities}

Several comorbidities were summarized for tabulation and multivariable logistic regression (MLR) as follows: cardiovascular disease, myocardial infarction, and congestive heart failure; chronic respiratory disease - chronic obstructive pulmonary disease and chronic lung disease; renal disease or dialysis, moderate to severe renal disorder, and maintenance hemodialysis before hospitalization; and leukemia/lymphoma. Body mass index (BMI) $\geq 25$ was considered obese.

\section{Age Class}

According to the Japan Geriatrics Society and the Japan Gerontological Society, age was divided into 3 categories: pre-old (65-74 years), old (75-89 years), and super-old ( $\geq 90$ years) [12].

\section{National Early Warning Score}

National Early Warning Score (NEWS) is a validated early warning score system composed of 6 physiological measurements (respiratory rate, oxygen saturation, body temperature, systolic blood pressure, heart rate, and level of consciousness) to assess patients at risk for early exacerbation. The NEWS determines its triage category for a clinical alert, requiring clinician assessment based on the score level: a low score (1-4), a medium score (5-6), and a high score (7 or more) [13]. We displayed the clinical course of elderly COVID-19 patients and subdivided into each NEWS category at admission.

\section{Respiratory Support during Hospitalization}

Respiratory support during hospitalization was classified into 3 categories: no oxygen, oxygen, and invasive mechanical ventilation (IMV)/extracorporeal membrane oxygenation (ECMO). Each category was defined by the following state of supplementary oxygen: no oxygen was supplied throughout hospitalization; oxygen - oxygen was supplied (including high-flow oxygen devices and non-IMV) during hospitalization; and IMV/ECO - IMV or ECMO was required during hospitalization. The amount of administered oxygen was grouped into bivariate variables: no/low and high. The no/low-dose group comprised those who received no oxygen, those who received oxygen by cannula, and those who received $<5 \mathrm{~L}$ of oxygen by a mask. The high-dose class comprised those who received $\geq 5 \mathrm{~L}$ of oxygen by a mask and those who received oxygen by a reservoir, high-flow oxygen device, or noninvasive/IMV. Severe illness was grouped into bivariate variables: severe and nonsevere. Patients who received a high dose of oxygen as defined above or died between 5 and 15 days after the onset were categorized as severe.

\section{Statistical Analysis}

Continuous variables are described as the medians and interquartile range and categorical variables in the number of cases and percentages. Comparisons among age-groups were conducted using the Kruskal-Wallis test for continuous variables and the $\chi^{2}$ test for categorical variables. MLR analyses were conducted to identify risk factors (RFs) for severe illness and factors associated with death. First, clinically important variables were investigated by study investigators. Variables of age, male sex, BMI, and comorbidities (cerebrovascular disease, collagen disease, dementia, diabetes, leukemia or lymphoma, liver disease, chronic lung disease or chronic obstructive pulmonary disease, myocardial infarction or congestive heart failure, metastatic sol- 
Table 1. Patients' characteristics

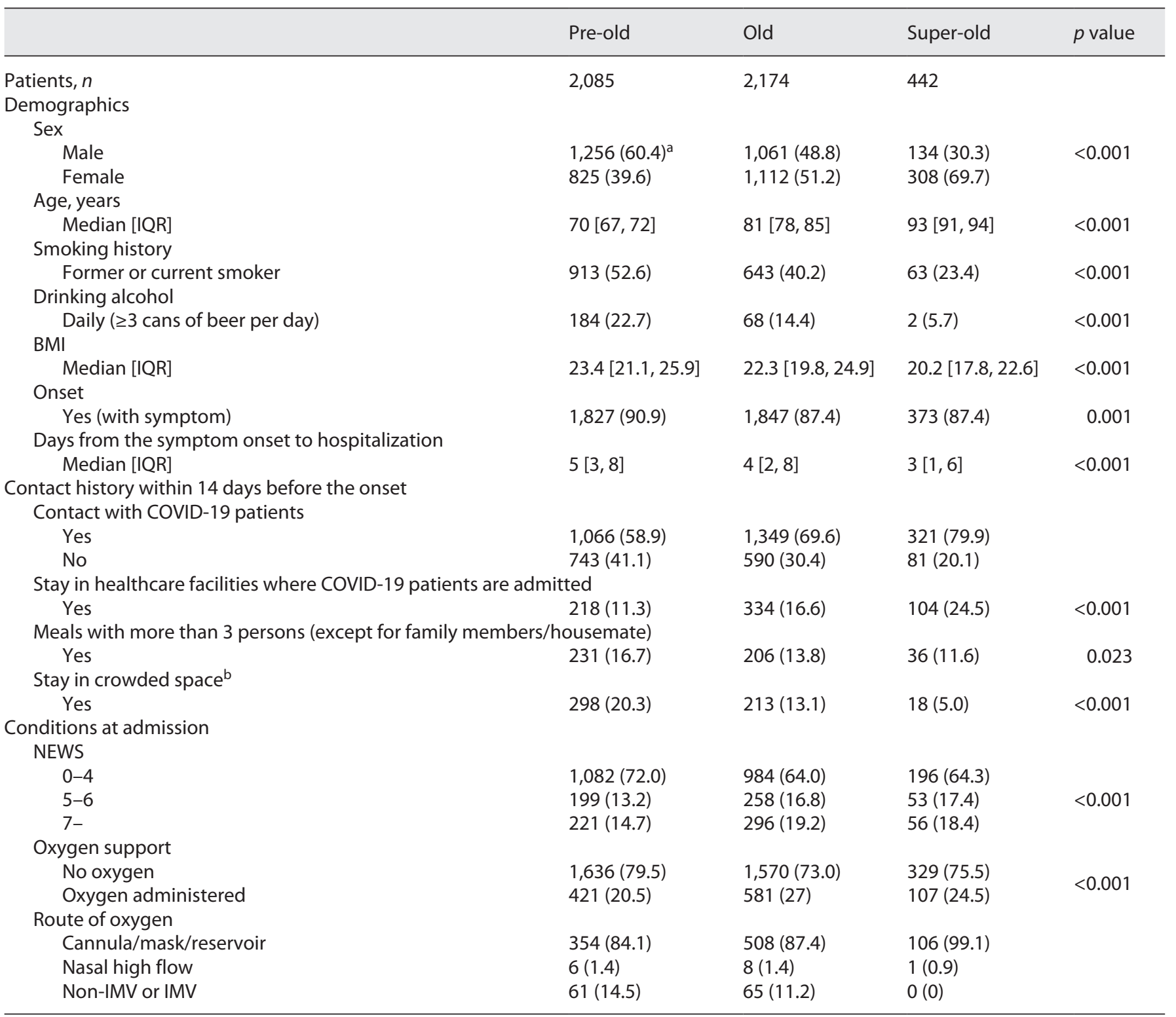

IQR, interquartile range. ${ }^{a}$ The denominator in each category depends on the number of missing values. ${ }^{b}$ Crowded space: sport gym, live music house, karaoke, game center, buffet, indoor party, conference, nightclub/bar, among others.

id tumor, paralysis, peptic ulcer, peripheral vascular disease, renal disease or dialysis, and solid tumor) were selected, and their multicollinearity was assessed by the variance inflation factor. When multicollinearity was observed (variance inflation factor $>3$ ), variables more associated with increased risk were chosen (however, no variables showed apparent collinearity in the following analysis). The variables of age, male sex, BMI, and comorbidities were included in the overall analysis and male sex, BMI, and comorbidities in the analysis within each age class. Forward stepwise logistic analysis was carried out when the number of patients was limited, and all the relevant variables could not be employed; the RFs were further selected based on AIC. R version 4.0.2 (R Core Team [14]) was used for all statistical analyses in this study.

Ethics

This study was approved by the NCGM Ethics Review. 


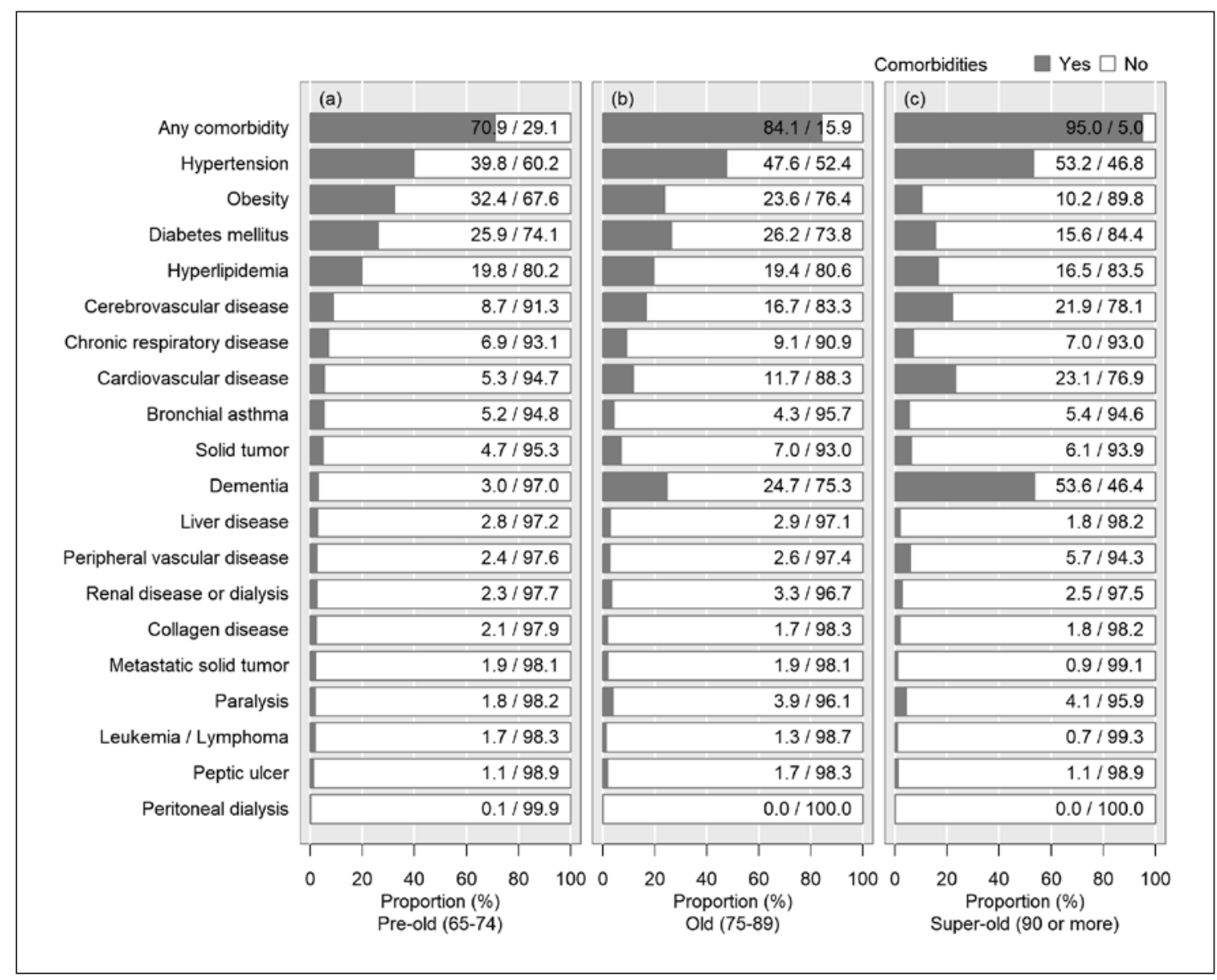

Fig. 1. a-c Comorbidities. The presence/absence of comorbidities reported at admission. Obesity was defined as a BMI of $\geq 25$.

\section{Results}

\section{Patients' Characteristics}

Data from 4,701 patients from 444 hospitals were included. Of them, 2,085 (44.3\%) were pre-old, 2,174 (46.2\%) were old, and 442 (9.4\%) were super-old. Due to missing values, the number of cases included in the following analyses might vary. Patient demographics and clinical characteristics are shown in Table 1 and Figure 1, respectively. The sex ratio of cases was almost equal $(2,451$ [52.2\%] males and 2,245 [47.8\%] females); however, the ratio in each age class varied, and more males were enrolled in the pre-old group $(1,256$ [60.4\%]), and more females in the super-old group (308 [69.7\%]).

The NEWS on admission was $<4$ in 2,262 (67.6\%) patients. A total of 3,535 (76.1\%) patients did not require additional oxygen on admission.
The number of patients who had contact with COVID-19 patients within 14 days before the onset was $2,736(65.9 \%)$, and the proportion tended to increase with age. Within 14 days of the symptom onset, there were 473 cases (14.9\%) who had group meals, defined as having meals with more than 3 persons except for family members, and 529 cases (15.3\%) who stayed in crowded spaces. The proportions in each age-group tended to decrease with increasing age. Conversely, the proportion of elderly patients staying in healthcare facilities increased with age.

Most patients (3,726 [79.3\%]) had at least one comorbidity, and the proportion of patients with hypertension was high in all age-groups. The proportion of patients with dementia, cardiovascular disease, and cerebrovascular disease increased with age. 
Table 2. Supportive care during hospitalization and outcome

\begin{tabular}{|c|c|c|c|c|}
\hline & Pre-old & Old & Super-old & $p$ value \\
\hline Patients, $n$ & 2,085 & 2,174 & 442 & \\
\hline \multicolumn{5}{|l|}{ Severity during hospitalization } \\
\hline No oxygen & $1,082(52)^{a}$ & $856(39.4)$ & $190(43)$ & \multirow{3}{*}{$<0.001$} \\
\hline Oxygen & $773(37.1)$ & $1,091(50.3)$ & $244(55.2)$ & \\
\hline IMV/ECMO & $227(10.9)$ & $224(10.3)$ & $8(1.8)$ & \\
\hline \multicolumn{5}{|l|}{ Outcome at discharge } \\
\hline Outcome & & & & \\
\hline Discharge or transfer & $1,974(94.7)$ & $1,843(84.8)$ & $342(77.6)$ & \multirow{2}{*}{$<0.001$} \\
\hline Dead & $110(5.3)$ & $330(15.2)$ & $99(22.4)$ & \\
\hline \multicolumn{5}{|l|}{ Details of outcome } \\
\hline Discharge & $1,540(73.9)$ & $1,070(49.2)$ & $118(26.8)$ & \\
\hline Transfer to a different hospital & $383(18.4)$ & $546(25.1)$ & $119(27)$ & \\
\hline Transfer to a nonmedical facility & $28(1.3)$ & $28(1.3)$ & $7(1.6)$ & \\
\hline Transfer to a long-term care facility & $23(1.1)$ & $199(9.2)$ & $98(22.2)$ & \\
\hline \multicolumn{5}{|l|}{ Tracheotomy } \\
\hline Yes & $37(1.9)$ & $27(1.5)$ & $0(0)$ & $<0.001$ \\
\hline \multicolumn{5}{|l|}{ Self-care ability } \\
\hline Stable or improved & $1,701(88.3)$ & $1,380(77.6)$ & $251(77)$ & \multirow{2}{*}{$<0.001$} \\
\hline Worsened & $225(11.7)$ & $399(22.4)$ & $75(23.0)$ & \\
\hline \multicolumn{5}{|l|}{ Supportive therapy during hospitalization } \\
\hline Yes & $299(14.3)$ & $324(14.9)$ & $30(6.8)$ & $<0.001$ \\
\hline \multicolumn{5}{|l|}{ Oxygen support } \\
\hline No oxygen & $1,082(52)$ & $856(39.4)$ & $190(43)$ & \multirow{2}{*}{$<0.001$} \\
\hline Oxygen administered & $1,000(48)$ & $1,315(60.6)$ & $252(57)$ & \\
\hline \multicolumn{5}{|l|}{ Route of oxygen } \\
\hline High-flow nasal cannula & $64(6.4)$ & $102(7.8)$ & $12(4.8)$ & \\
\hline Non-IMV & $31(3.1)$ & $39(3)$ & $7(2.8)$ & \\
\hline IMV & $197(19.7)$ & $219(16.7)$ & $8(3.2)$ & \\
\hline ECMO & $30(3)$ & $5(0.4)$ & $0(0)$ & \\
\hline Other & $678(67.8)$ & $950(72.2)$ & $225(89.3)$ & \\
\hline \multicolumn{5}{|l|}{ Number of the death after oxygen support } \\
\hline High-flow nasal cannula & $7(10.9)$ & $36(35.3)$ & $5(41.7)$ & \\
\hline Non-IMV & $4(12.9)$ & $13(33.3)$ & $4(57.1)$ & \\
\hline IMV & $48(24.4)$ & $100(45.7)$ & $6(75)$ & \\
\hline ECMO & $15(50)$ & $2(40)$ & $0(-)$ & \\
\hline \multicolumn{5}{|l|}{ Inotropic } \\
\hline Yes & $117(5.6)$ & $144(6.6)$ & $8(1.8)$ & $<0.001$ \\
\hline \multicolumn{5}{|l|}{ RRT or dialysis } \\
\hline Yes & $61(2.9)$ & $56(2.6)$ & $1(0.2)$ & $<0.001$ \\
\hline \multicolumn{5}{|l|}{ Blood transfusion } \\
\hline Yes & $109(5.2)$ & $120(5.5)$ & $15(3.4)$ & 0.181 \\
\hline
\end{tabular}

RRT, renal replacement therapy; ICU, intensive care unit. ${ }^{a}$ The denominator in each category depends on the number of missing values.

\section{Supportive Care and Outcomes}

Among 4,695 patients, 2,128 (45.3\%) did not require additional oxygen during hospitalization (Table 2). The number of patients who received oxygen during hospitalization was 2,567 $(54.7 \%)$ and that of who underwent IMV/ECMO was 459 (17.9\%). Among those who re- ceived supportive oxygen through high-flow devices or IMV, 48 (27.0\%) and 154 (36.3\%) patients died, respectively. A total of $4,159(88.5 \%)$ patients were discharged or transferred to different hospitals, nonmedical facilities, or long-term care facilities. 


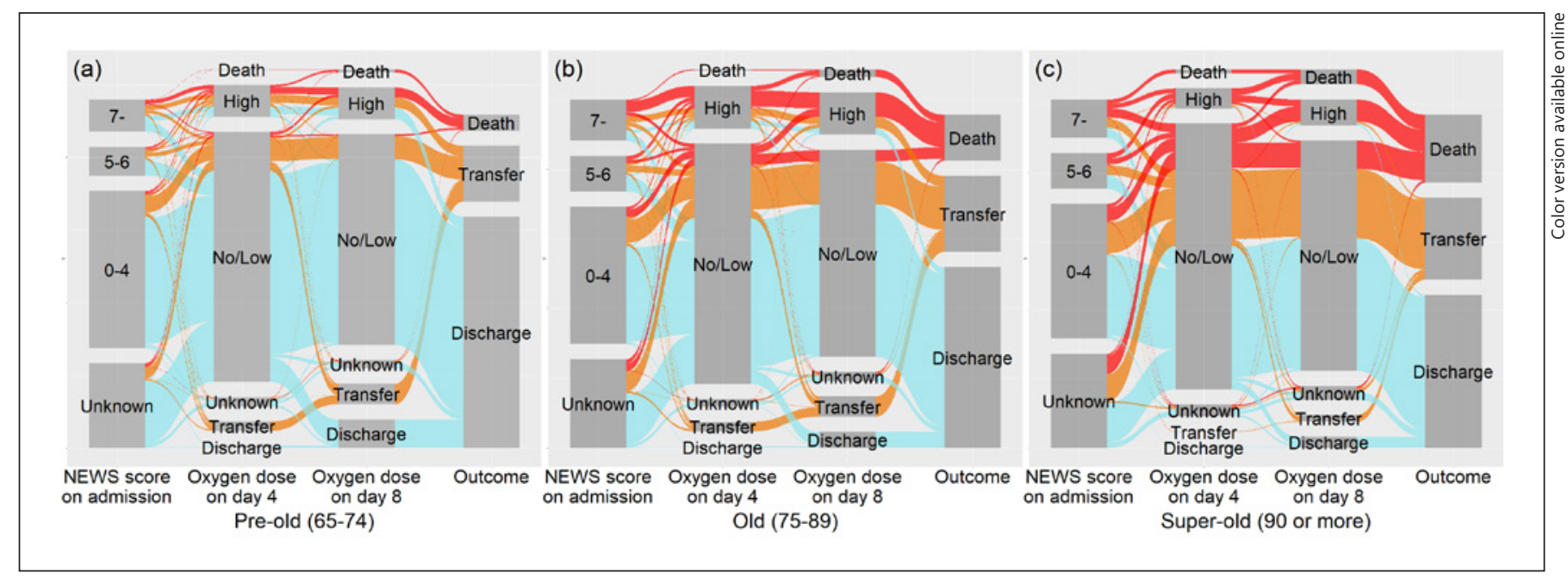

Fig. 2. a-c Progression of patients' severity and administration of supportive oxygen on day 4/8 after admission. A no/low oxygen dose consisted of those who received no oxygen, those who received oxygen by cannula, and those who received $<5 \mathrm{~L}$ of oxygen by mask. A high oxygen dose consisted of those who received $\geq 5 \mathrm{~L}$ of oxygen by a mask and those who received oxygen by a reservoir, high-flow oxygen device, or non-IMV/IMV.

Figure 2 illustrates the progression of severity and dose of administered oxygen on days 4 and 8 after admission. Many of the patients with a NEWS lower than 4 were discharged; however, the proportion of patients discharged tended to decrease with increasing age. The proportion of patients who died among those with a NEWS of $>7$ increased with age. In the pre-old group, more than $50 \%$ of the patients were discharged or transferred to other hospitals after receiving a high dose of oxygen on days 4 or 8 . In contrast, most of the patients who received a high dose of oxygen died in the super-old group (23 [79.3\%] on day 4 and 32 [84.2\%] on day 8$)$.

\section{RFs for Severe Illness}

RFs for severe illness are listed in Figure 3. Overall, age (OR $1.05[1.04,1.07])$ and sex (OR $2.23[1.80,2.77])$ were considered to increase risk. Among the comorbidities, obesity $(\mathrm{BMI} \geq 25)(\mathrm{OR} 2.05[1.65,2.55])$, collagen disease (OR 2.77 [1.50, 5.01]), diabetes (OR 1.41 [1.14, 1.74]), liver disease (OR 1.89 [1.14, 3.09]), leukemia and lymphoma (OR $3.63[1.85,6.96])$, chronic respiratory disease (OR $1.87[1.37,2.55]$ ), metastatic solid tumor (OR 2.44 [1.29, $4.51]$ ), and renal disease or dialysis (OR $2.28[1.37,3.75]$ ) were found to be significant RFs. Multivariate logistic regression in the pre-old and the old classes showed a similar trend. In the super-old group, collagen disease, renal disease or dialysis, and sex were selected after stepwise analysis. In addition, it was shown that male sex was a RF for all age-groups. Most of the significant factors in Fig- ure 3 were also considered to be RFs associated with death (online suppl. Fig. 1; for all online suppl. material, see www.karger.com/doi/10.1159/000521000). Among them, sex was significant in all age-groups.

\section{Administered Drug}

The data for the administered drug are summarized in online supplementary Figure 1. Steroids were most likely to be used in the old (32.8\%), pre-old (26.4\%), and superold (23.9\%) groups. Remdesivir was used less frequently in the super-elderly $(9.7 \%)$ than in the other 2 groups (pre-old, 17.8\%; old, 19\%). Favipiravir was used similarly among the groups (66.5-68.2\%).

\section{Discussion}

Our study revealed clear differences in epidemiological and clinical characteristics among the different agegroups. When discussing the risk of infectious diseases, populations aged 60 or 65 years or older have been grouped together as elderly [15]. The prognosis in populations aged 65 years and older is worse than that in younger populations, and the elderly population is generally at higher risks [16-18]. Conversely, Japan is one of the super-aging societies in the world, with 15.6 million men $(25.4 \%)$ and 20.2 million women (31.3\%) aged 65 years and over, accounting for $28.4 \%$ of the total population [19]. The pre-old population in this study was tradi- 


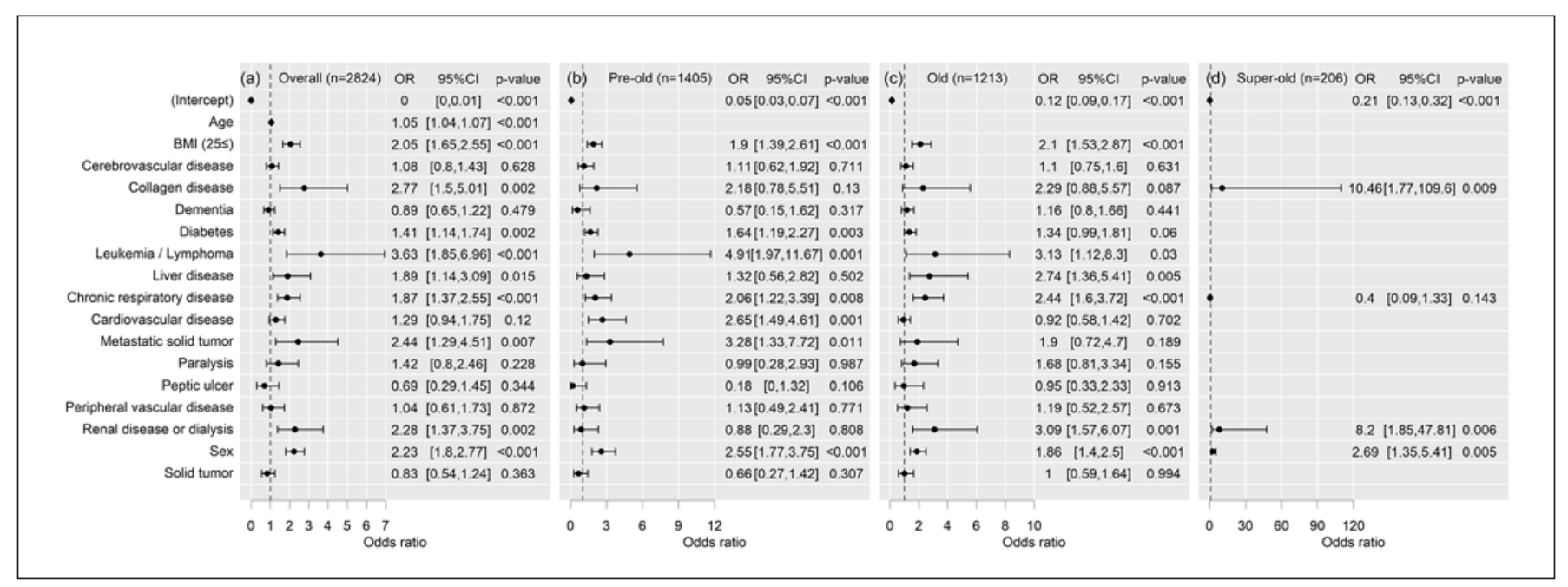

Fig. 3. a-d RFs for severe illness among elderly patients. Cardiovascular disease: myocardial infarction and congestive heart failure. Chronic respiratory disease: COPD and chronic lung disease. Renal disease or dialysis: moderate to severe renal disorder and maintenance hemodialysis before hospitalization. COPD, chronic obstructive pulmonary disease.

tionally considered to be the elderly; however, many of them are still active in society. Therefore, the heterogeneity of health and activity status makes it difficult to discuss the group aged $\geq 65$ years. Thus, we divided the elderly population of Japan into 3 groups: pre-old (65-74 years), old (75-89 years), and super-old ( $\geq 90$ years) and investigated RFs, treatments, outcomes, and their differences within and among these groups.

The epidemiological characteristics before infection were different among each age-group. The pre-old group was more likely to have eaten out with nonfamily members (16.7\%) and to have been in crowded spaces (20.3\%). Although it is unclear where the actual infection occurred, the pre-old population in Japan is usually still active, suggesting that the infection might be transmitted through social activities. On the other hand, more patients in the old and the super-old groups had stayed in healthcare facilities where COVID-19 patients were admitted within 14 days prior to the symptom onset. In particular, the proportion of such cases in the super-old group was $24.5 \%$, which might reflect the impact of nosocomial infections in the super-old group, which has been frequently reported in the current COVID-19 outbreak $[20,21]$.

The proportion of elderly patients who required oxygenation at admission and during hospitalization was lower in our study than that in a prior study [22], which means that our study had milder cases. This could be due to the specific situation in Japan during the study period, where medical capacity was not overwhelmed, and longterm care facilities and home care schemes were still insufficient. Under these circumstances, most elderly patients were admitted to the hospital, regardless of the severity of COVID-19. Therefore, even milder cases had an opportunity to be hospitalized.

In the elderly, besides death in the acute phase caused by COVID-19, deaths due to various complications after COVID-19 can occur. Therefore, in this study, we considered it necessary to analyze a broader range of serious conditions, not just death, to identify the RFs associated with severe acute COVID-19. Thus, patients who received high-dose oxygen or died between 5 and 15 days after the onset of illness were considered to be severely ill, and the RFs among them were examined. The RFs of severe disease in elderly patients as a whole were male sex, age, obesity, collagen disease, diabetes, liver disease, leukemia/lymphoma, chronic respiratory disease, metastatic cancer, and moderate to severe renal dysfunction/dialysis. A previous meta-analysis showed that patients aged 70 years and above have higher risks of COVID-19 in different severity stages [23], and overlapping comorbidities with our study results revealed RFs for severe disease [24, $25]$. The same conditions were also identified as being associated with severe diseases in a large, hospitalized patient cohort in Japan [10]. On the other hand, when assessing the RFs associated with severe disease by different age-groups, not all ages were uniform, and RFs associated with severe disease varied between different age-groups. 
These results suggest that comorbidities contributed to the severity of elderly COVID-19 patients in a complex manner.

MLR showed that male sex was a common RF in all ages of elderly patients. The ratio of females to males in the elderly population in Japan is 1:1.09 in the pre-old, 1:1.41 in the old, and 1:3 in the super-old population, and the ratio of females to males tends to increase with increased age. The proportion of females in this study was higher in the super-old population (69.7\% compared to $30.3 \%$ for males), possibly suggesting that the different lifetime between men and women is reflected in the number of COVID-19 cases. Conversely, more males (60.4\%) than females (39.6\%) were admitted to the pre-old agegroup. In this age-group, $76.3 \%$ of men and $62.5 \%$ of women had at least one underlying disease, and the NEWS at the time of admission was $3[1,5]$ for men and $2[0,4]$ for women, suggesting that more males were hospitalized as symptomatic patients. These results suggest an increased risk of acquiring infection and an increased likelihood of severe disease in elderly men in our cohort. Biological, psychological, and behavioral factors have been suggested to increase the risk of infection, mortality, and disease severity in men $[26,27]$.

Hematological malignancies, including leukemia and lymphoma, and metastatic tumors were important RFs for severe disease in the elderly, but they dropped out of the list in the super-elderly. These results might be because there were fewer cases of these diseases in older patients; however, the previous study also suggested a worse outcome in younger hematological malignancy patients with COVID-19 than that in older patients [28]. According to a multicenter cohort study in Italy, the standardized mortality ratio was $2.04 \%$ (95\% confidence interval, 1.77-2.34) in COVID-19 patients with hematological malignancies, compared with the general Italian population with COVID-19 [28]. In addition, in their cohort of COVID-19 patients with hematological malignancies, the standardized mortality in patients younger than 70 years was higher than that in patients aged 70 years or older (3.72 compared to 1.71). Patients younger than 70 years could be eligible for definitive treatments, including hematopoietic stem-cell transplantation. Therefore, the differences in outcomes at younger ages may be influenced by the treatment of hematological malignancies. A prior prospective cohort study showed high mortality in COVID-19 patients with metastatic tumors [29]. Older age was associated with higher mortality in cancer patients [30], but there is a lack of research on which agegroups in the elderly patients specifically contribute to poor prognosis. Although this is beyond the scope of our study, further investigation of the differences in cancer types and treatments by different age-groups may provide new insights.

Collagen disease and moderate to severe renal dysfunction/dialysis were major risks for severe disease in older patients. Former robust data of clinical outcomes in COVID-19 patients with collagen diseases are insufficient [31]. Some reports suggested that rheumatic diseases did not change the mortality in COVID-19 but tended to increase the risk of respiratory failure $[32,33]$. According to a study from the COVID-19 Global Rheumatology Alliance, the use of high-dose glucocorticoids $(\geq 10 \mathrm{mg} /$ day of prednisolone-equivalent) was associated with hospitalization [34]. Conversely, the use of conventional disease-modifying antirheumatic drugs alone or in combination with biologics/Janus kinase inhibitors was not related to hospitalization. The activity of collagen diseases and drug use has not been investigated in this study and needs to be confirmed in more detail in the future. Patients with chronic renal dysfunction or receiving maintenance dialysis were shown to be highly vulnerable to COVID-19, resulting in a death rate of over 20\% [35-37]. Moreover, multiple concomitant comorbidities with end-stage renal disease could increase the risk of poor outcomes in COVID-19 patients.

Dementia was not detected as a RF for severe COVID-19 in our study. However, previous COVID-19 studies showed that dementia was associated with higher risks for hospitalization and death due to COVID-19 [38, 39]. On the other hand, some studies reported that dementia was not associated with higher mortality in superelderly patients $[40,41]$. There are several possible explanations for the dissociation between these analyses. First, in super-elderly patients, mortality from other comorbidities may be higher, and the impact of dementia may be less. Next, elderly patients may not only become severely ill in the acute phase of COVID-19 but may also become severely ill from new hospital-acquired complications in the late stage from the onset of COVID-19. In our study, to distinguish early severe disease caused by COVID-19 from other complications in the late stage, we used the most severe condition within 15 days of admission as an indicator of severe disease. Our results might suggest that many elderly patients become severely ill due to subsequent complications rather than COVID-19 itself. Finally, in Japan, the local health center takes responsibility for the indications for hospitalization of COVID-19 patients. During the period of data collection, the hospitalization threshold for the elderly was low. In addition, all hospi- 
talization and treatment costs were paid by the government. This background might lead to less unmeasured confounding (e.g., socioeconomic determinants), which might affect the outcome of COVID-19 patients with dementia in other studies.

In our study, the older the patient, the worse the prognosis. Not only did the percentage of deaths increase, but the percentage of patients who could be discharged home also decreased. Conversely, supportive care also varied by age, with invasive procedures, including IMV, being applied less frequently with increasing age, with approximately $10 \%$ of pre-old and old patients receiving IMV, compared to only $1.8 \%$ of super-old patients. To our knowledge, previous data on the super-old cohort are not available; however, the data from Korea using different age categories suggest that patients $\geq 80$ years of age were less likely to receive IMV than those of 65-69 or 70-79 years of age [42]. The previous data also suggested that more than half of the patients were deceased despite receiving IMV $[42,43]$. Decision-making regarding the treatment of the elderly involves several factors, including proficiency of medical personnel, harm/benefits of the treatment, expected prognosis, and the patient's preference regarding care [44]. Furthermore, in many regions, medical resources have been another issue in the current outbreak [4548]. Future studies are needed to determine the factors that influence the extent to which clinicians provide treatment in elderly patients.

There were some limitations because of the observational nature of the study [11]. The data entered in this registry were from patients who were discharged from medical institutions, which may not reflect the situation of some patients who needed to be hospitalized for a long time. In addition, specific treatments, including medicines for each disease, were not investigated, which may not reflect the heterogeneity of the population with certain comorbidities. Finally, the data registered in our study were insufficient to analyze the association between frailty and the degree of dependence of the elderly and RFs for severe COVID-19. Previous studies have suggested that these indicators could be independent RFs for severe COVID-19 in the elderly $[49,50]$. Especially in the very elderly, these indicators may be important in predicting the prognosis of COVID- 19.

In conclusion, in the elderly population, there were differences in epidemiological and clinical characteristics among the different age-groups. The optimal management of COVID-19 in the elderly requires further study.

\section{Acknowledgment}

The authors thank all the participating facilities for their care of patients with COVID-19 and their cooperation in data entry into the registry.

\section{Statement of Ethics}

Our study data were provided by Research Electronic Data Capture, a secure, Web-based data capture application hosted at the JCRAC Data Center of the NCGM. The opt-out recruitment method was applied, and informed consents for individuals were waived as approved by the NCGM Ethics Review. Information about the entire research was disclosed through the website (https://covid-registry.ncgm.go.jp/). This study was approved by the NCGMEthics Review (approval number:NCGM-G-003494-0).

\section{Conflict of Interest Statement}

H. Ohtsu reports personal fees as a statistician and as an external consultant for clinical trials from EPS International, outside the submitted work. S. Saito reports grants from Shionogi outside the submitted work. The other authors have no conflicts of interest to disclose.

\section{Funding Sources}

This research was supported by the Health and Labor Sciences Research Grant, "Research on Emerging and Re-emerging Infectious Diseases and Immunization" under grant No. 19HA1003 and by AMED under grant No. 20ek0210106h0003.

\section{Author Contributions}

Y. Asai, H. Nomoto, and K. Hayakawa developed the concept and design and had full access to all the data in the study and took responsibility for the integrity of the data and the accuracy of the data analysis. Y. Asai and S. Tsuzuki were responsible for the statistical analysis. N. Matsunaga, S. Tsuzuki, M. Terada, H. Ohtsu, K. Kitajima, K. Suzuki, S. Saito, F. Saito, K. Nakamura, T. Suzuki, and S. Morioka provided administrative, technical, or material support. N. Ohmagari supervised the study. All the authors critically revised the manuscript for important intellectual content.

\section{Data Availability Statement}

The data that support the findings of this study are not publicly available due to the privacy of research participants and sites but are available upon reasonable request. Data on an individual level are shared with limitations to participating healthcare facilities through applications to the COVIREGI-JP. 


\section{References}

1 World Health Organization. Weekly epidemiological update [Internet]. 2021 Mar 2. Available from: https://www.who.int/ publications/m/item/weekly-epidemiological-update.

2 Saito S, Asai Y, Matsunaga N, Hayakawa K, Terada M, Ohtsu H, et al. First and second COVID-19 waves in Japan: a comparison of disease severity and characteristics. J Infect. 2021 Apr;82(4):84-123.

3 National Institute of Infectious Diseases. Current situation of infection [Internet]. 2021 Feb 11. Available from: https://www.niid.go.jp/ niid/en/2019-ncov-e/10196-covid19-ab23then.html.

4 Ministry of Health, Labour and Welfare. Situation report [Internet]. 2021. https://www. mhlw.go.jp/stf/covid-19/kokunainohasseijoukyou_00006.html.

5 O'Driscoll M, Ribeiro Dos Santos G, Wang L, Cummings DAT, Azman AS, Paireau J, et al. Age-specific mortality and immunity patterns of SARS-CoV-2. Nature. 2021 Feb; 590(7844):140-5.

6 Pastor-Barriuso R, Pérez-Gómez B, Hernán MA, Pérez-Olmeda M, Yotti R, Oteo-Iglesias $\mathrm{J}$, et al. Infection fatality risk for SARS-CoV-2 in community dwelling population of Spain: nationwide seroepidemiological study. BMJ. 2020 Nov; 371:m4509.

7 Perez-Saez J, Lauer SA, Kaiser L, Regard S, Delaporte E, Guessous I, et al. Serology-informed estimates of SARS-CoV-2 infection fatality risk in Geneva, Switzerland. Lancet Infect Dis. 2021 Apr;21(4):e69-70.

8 Jordan RE, Adab P, Cheng KK. COVID-19: risk factors for severe disease and death. BMJ. 2020 Mar;368:m1198.

9 Ministry of Health, Labour and Welfare. Life expectancies at birth in some countries [Internet]. 2019. https://www.mhlw.go.jp/english/ database/db-hw/lifetb19/dl/lifetb19-03.pdf.

10 Matsunaga N, Hayakawa K, Terada M, Ohtsu $\mathrm{H}$, Asai Y, Tsuzuki S, et al. Clinical epidemiology of hospitalized patients with COVID-19 in Japan: report of the COVID-19 Registry Japan. Clin Infect Dis. 2020 Sep. Epub ahead of print.

11 Harris PA, Taylor R, Thielke R, Payne J, Gonzalez N, Conde JG. Research electronic data capture (REDCap) - a metadata-driven methodology and workflow process for providing translational research informatics support. J Biomed Inform. 2009 Apr;42(2):37781.

12 Ouchi Y, Rakugi H, Arai H, Akishita M, Ito H, Toba K, et al. Redefining the elderly as aged 75 years and older: proposal from the Joint Committee of Japan Gerontological Society and the Japan Geriatrics Society. Geriatr Gerontol Int. 2017 Jul;17(7):1045-7.
13 National early warning score (NEWS). Standardising the assessment of acute-illness severity in the NHS. 2021. Available from: file: ///Users/nomoto/Downloads/National\%20 E a r ly \% $20 \mathrm{~W}$ arning $\% 20 \mathrm{Score} \% 20$ (NEWS)\%20-\%20Standardising\%20the\%20 assessment $\% 20 \mathrm{of} \% 20$ acute-illness $\% 20$ severity\%20in\%20the\%20NHS_0.pdf.

14 R Core Team. R: a language and environment for statistical computing [Internet]. Vienna, Austria: R Foundation for Statistical Computing; 2020. Available from: https://www.Rproject.org/.

15 World Health Organization. Men, ageing and health: achieving health across the life span [Internet]. 2001. Available from: https:// www.who.int/ageing/publications/men/en/.

16 Liu K, Chen Y, Lin R, Han K. Clinical features of COVID-19 in elderly patients: a comparison with young and middle-aged patients. J Infect. 2020 Jun;80(6):e14-8.

17 Wang L, He W, Yu X, Hu D, Bao M, Liu H, et al. Coronavirus disease 2019 in elderly patients: characteristics and prognostic factors based on 4-week follow-up. J Infect. 2020 Jun; 80(6):639-45

18 Ho FK, Petermann-Rocha F, Gray SR, Jani BD, Katikireddi SV, Niedzwiedz CL, et al. Is older age associated with COVID-19 mortality in the absence of other risk factors? General population cohort study of 470,034 participants. PLoS One. 2020 Nov; 15(11): e0241824

19 Statistics Bureau of Japan. Current population estimates as of October 1, 2019 [Internet]. 2019. Available from: https://www.stat. go.jp/english/data/jinsui/2019np/index. html\#a15k01-a.

20 Rhee C, Baker M, Vaidya V, Tucker R, Resnick A, Morris CA, et al. Incidence of nosocomial COVID-19 in patients hospitalized at a large US academic medical center. JAMA Netw Open. 2020 Sep 1;3(9):e2020498.

$21 \mathrm{Yu}$ J, Ouyang W, Chua MLK, Xie C. SARSCoV-2 transmission in patients with cancer at a tertiary care hospital in Wuhan, China. JAMA Oncol. 2020 Jul;6(7):1108-10.

22 Singhal S, Kumar P, Singh S, Saha S, Dey AB Clinical features and outcomes of COVID-19 in older adults: a systematic review and metaanalysis. BMC Geriatr. 2021 May;21(1):321.

23 Pijls BG, Jolani S, Atherley A, Derckx RT, Dijkstra JIR, Franssen GHL, et al. Demographic risk factors for COVID-19 infection, severity, ICU admission and death: a meta-analysis of 59 studies. BMJ Open. 2021;11(1):e044640.

24 CDC COVID-19 Response Team. Severe outcomes among patients with coronavirus disease 2019 (COVID-19) - United States, February 12-March 16, 2020. MMWR Morb Mortal Wkly Rep. 2020 Mar;69(12):343-6.
$25 \mathrm{Wu}$ Z, McGoogan JM. Characteristics of and important lessons from the Coronavirus disease 2019 (COVID-19) outbreak in China: summary of a report of 72314 cases from the Chinese Center for Disease Control and Prevention. JAMA. 2020 Apr;323(13):1239-42.

26 Peckham H, de Gruijter NM, Raine C, Radziszewska A, Ciurtin C, Wedderburn LR, et al. Male sex identified by global COVID-19 meta-analysis as a risk factor for death and ITU admission. Nat Commun. 2020 Dec; 11(1):6317.

27 Griffith DM, Sharma G, Holliday CS, Enyia OK, Valliere M, Semlow AR, et al. Men and COVID-19: a biopsychosocial approach to understanding sex differences in mortality and recommendations for practice and policy interventions. Prev Chronic Dis. 2020 Jul;17: E63.

28 Passamonti F, Cattaneo C, Arcaini L, Bruna R, Cavo M, Merli F, et al. Clinical characteristics and risk factors associated with $\mathrm{CO}$ VID-19 severity in patients with haematological malignancies in Italy: a retrospective, multicentre, cohort study. Lancet Haematol. 2020 Oct; $7(10): \mathrm{e} 737-45$.

29 Dai M, Liu D, Liu M, Zhou F, Li G, Chen Z, et al. Patients with cancer appear more vulnerable to SARS-CoV-2: a multicenter study during the COVID-19 Outbreak. Cancer Discov. 2020 Jun;10(6):783-91.

30 Lee LYW, Cazier JB, Starkey T, Briggs SEW, Arnold R, Bisht V, et al. COVID-19 prevalence and mortality in patients with cancer and the effect of primary tumour subtype and patient demographics: a prospective cohort study. Lancet Oncol. 2020 Oct;21(10):130916.

31 Fitzgerald GE, Maguire S, Haroon N. COVID-19: what do rheumatologists need to know? Curr Rheumatol Rep. 2021 Jan;23(1):5.

32 D'Silva KM, Serling-Boyd N, Wallwork R, Hsu T, Fu X, Gravallese EM, et al. Clinical characteristics and outcomes of patients with coronavirus disease 2019 (COVID-19) and rheumatic disease: a comparative cohort study from a US "hot spot." Ann Rheum Dis. 2020 Sep;79(9):1156-62.

33 Ye C, Cai S, Shen G, Guan H, Zhou L, Hu Y, et al. Clinical features of rheumatic patients infected with COVID-19 in Wuhan, China. Ann Rheum Dis. 2020 Aug;79(8):1007-13.

34 Gianfrancesco M, Hyrich KL, Al-Adely S, Carmona L, Danila MI, Gossec L, et al. Characteristics associated with hospitalisation for COVID-19 in people with rheumatic disease: data from the COVID-19 Global Rheumatology Alliance physician-reported registry. Ann Rheum Dis. 2020 Jul;79(7):859-66.

35 Hsu CM, Weiner DE, Aweh G, Miskulin DC, Manley HJ, Stewart C, et al. COVID-19 infection among US dialysis patients: risk factors and outcomes from a national dialysis provider. Am J Kidney Dis. 2021 Jan;77(5):74856.e1. 
36 Weiss S, Bhat P, Del Pilar Fernandez M, Bhat JG, Coritsidis GN. COVID-19 infection in ESKD: findings from a prospective disease surveillance program at dialysis facilities in New York City and Long Island. J Am Soc Nephrol. 2020 Nov;31(11):2517-21.

37 Valeri AM, Robbins-Juarez SY, Stevens JS, Ahn W, Rao MK, Radhakrishnan J, et al. Presentation and outcomes of patients with ESKD and COVID-19. J Am Soc Nephrol. 2020 Jul;31(7):1409-15.

38 July J, Pranata R. Prevalence of dementia and its impact on mortality in patients with coronavirus disease 2019: a systematic review and meta-analysis. Geriatr Gerontol Int. 2021 Feb; 21(2):172-7.

39 Wang Q, Davis PB, Gurney ME, Xu R. COVID-19 and dementia: analyses of risk, disparity, and outcomes from electronic health records in the US. Alzheimers Dement. 2021; 17(8):1297-306.

40 Miyashita S, Yamada T, Mikami T, Miyashita $\mathrm{H}$, Chopra N, Rizk D. Impact of dementia on clinical outcomes in elderly patients with coronavirus 2019 (COVID-19): an experience in New York. Geriatr Gerontol Int. 2020 Jul;20(7):732-4.
41 De Smet R, Mellaerts B, Vandewinckele H, Lybeert P, Frans E, Ombelet S, et al. Frailty and mortality in hospitalized older adults with COVID-19: retrospective observational study. J Am Med Dir Assoc. 2020 Jul;21(7): 928-32.e1.

42 Lee JY, Kim HA, Huh K, Hyun M, Rhee JY, Jang S, et al. Risk factors for mortality and respiratory support in elderly patients hospitalized with COVID-19 in Korea. J Korean Med Sci. 2020 Jun;35(23):e223.

43 Cummings MJ, Baldwin MR, Abrams D, Jacobson SD, Meyer BJ, Balough EM, et al. Epidemiology, clinical course, and outcomes of critically ill adults with COVID-19 in New York City: a prospective cohort study. Lancet. 2020 Jun;395(10239): 1763-70.

44 Guiding principles for the care of older adults with multimorbidity: an approach for clinicians: American Geriatrics Society expert panel on the care of older adults with multimorbidity. J Am Geriatr Soc. 2012 Oct;60(10): E1-25.

45 Shoukat A, Wells CR, Langley JM, Singer BH, Galvani AP, Moghadas SM. Projecting demand for critical care beds during COVID-19 outbreaks in Canada. CMAJ. 2020 May; 192(19):E489-96.
46 Li R, Rivers C, Tan Q, Murray MB, Toner E, Lipsitch M. Estimated demand for US hospital inpatient and intensive care unit beds for patients with COVID-19 based on comparisons with Wuhan and Guangzhou, China. JAMA Netw Open. 2020 May;3(5):e208297.

47 Mitsuya H. Fight against COVID-19 but avoid disruption of services for other communicable diseases (CDs) and noncommunicable diseases (NCDs). Glob Health Med. 2020 Dec;2(6):343-5.

48 Kokudo N, Sugiyama H. Hospital capacity during the COVID-19 pandemic. Glob Health Med. 2021;3(2):56-9.

49 Aw D, Woodrow L, Ogliari G, Harwood R. Association of frailty with mortality in older inpatients with COVID-19: a cohort study. Age Ageing. 2020 Nov;49(6):915-22.

50 Blomaard LC, van der Linden CMJ, van der Bol JM, Jansen SWM, Polinder-Bos HA, Willems HC, et al. Frailty is associated with inhospital mortality in older hospitalised COVID-19 patients in the Netherlands: the COVID-OLD study. Age Ageing. 2021 May 5; 50(3):631-40. 